eISSN: 2659-6482

DOI: https://doi.org/10.14201/pmrt.19174

\title{
MÚSICA CLÁSICA, SERIOUS MUSIC O MÚSICA CULTA EN LA SERIE DE TELEVISIÓN: MERLÍ. \\ Ni graffiti del presente, ni estampita del pasado ${ }^{1}$
}

\section{Classical music, serious music or cultured music in the television series: Merlí. \\ Nor graffiti of the present, neither holy card of the past}

\author{
Marta MILLÀ I BRUCH \\ Universidad de Salamanca \\ mmilla.k@ccma.cat
}

RESUMEN: En el ámbito de los medios audiovisuales, podemos comprobar cómo el uso de la música clásica es frecuente. Podríamos poner algún ejemplo reciente en nuestra memoria audiovisual de anuncios publicitarios, películas o documentales que usan este género musical con cierta finalidad significativa y evocativa. Sin embargo, en algunos casos en los que el producto audiovisual va dirigido a un público objetivo que no muestra un interés explícito en la música clásica, puede llegar a sorprender el poder de atracción y el cambio significativo que aporta a las imágenes o secuencias.

A partir de la serie Merlí, en su primera temporada, propongo un análisis del uso de música clásica a través de diversas secuencias que aparecen en cada uno de los capítulos. Entre un Preludio, en el que introduzco elementos a tener a en cuenta antes de abordar el montaje sonoro, y un Postludio, en el que desarrollo las conclusiones del estudio, realizo un análisis del uso expresivo y el uso narrativo de la música clásica a partir de los distintos tipos de montaje de vídeo. Para ello, no sólo profundizo en cada una de las secuencias de la serie respecto a la simbiosis «imagen-música clásica»

1. Baricco, Alessandro (1992). El alma de Hegel y las vacas de Wisconsin, Madrid: Ediones Siruela (p. 27) 
sino que también incluyo el desarrollo del guión dentro de una serie cuyo target o público objetivo principal son los adolescentes o jóvenes. En definitiva, descubrir cómo la música clásica ya no es «estampita del pasado» ni «graffiti del presente».

Palabras clave: Audiovisual; serie; música; Merlí; significante; semiótica; diégesis; narración; expresión; emoción; «Mickey Mousing»; banda sonora.

ABSTRACT: In the research field on audiovisual media, we can see how the classical music is often used to illustrate images. We could take as an example some advertisements, films or documentaries which use this musical genre with a significant and evocative purpose. However, in some cases where the audiovisual is aimed at a target audience that does not show an explicit interest in classical music, it may surprise the power of attraction and the significant change it brings to images or video sequences.

In this article, I propose an analysis of the use of classical music through various sequences of the television serie Merli in its first season of broadcasting. Between a Prelude, in which I introduce elements that musical designer should consider before editing the sound, and a Postlude, in which I develop the conclusions of the study, I analyse the expressive use and narrative use of classical from different types of video montage.

To develop this analysis, I not only delve into each of the sequences in Merlí in relation to the symbiosis «image-classical music» but I also include the development of the script within a TV serie whose target or main target audience are adolescents or young people. In short, discover how classical music is no longer «stamp of the past» or "graffiti of the present.»

Keywords: Audiovisual; serie; television; music; Merli; signifier; semiotics; diegesis; narration; expression; emotion; «Mickey Mousing»; soundtrack; aesthetics.

\section{PRELUDIO}

Siempre resulta complicado realizar un análisis fílmico-musical desde la vertiente estética del ensamblaje de dos disciplinas artísticas: la Música y el Cine (o imágenes). Desentrañar los significados del uso de la música dentro de un film no debería ser un estudio a posteriori debido a la multiplicidad de factores que han podido intervenir en la creación de una banda sonora. En nuestro caso, una serie filmada para ser vista a través de la televisión, estos factores pueden tener un 
origen tan banal como los gustos estéticos del realizador/director ${ }^{2}$. El deseo de emplear una música que, para el realizador, tiene un significado muy personal, de repente se transforma en un uso imprescindible de la música en cuestión, pero no aporta una significación estética que ayude al espectador a entrar en un mundo en que la simbiosis imagen-música le conduzca hacia una percepción emocional o intelectual que le enriquezca individualmente. A veces, no se trata de los gustos personales del director, sino que son otras causas las que conducen, no sólo al empleo de una música incidental en particular, sino al momento o duración en el tiempo de dicha música.

A continuación, enumero cinco factores, previos al uso musical y su edición junto con la imagen, que acontecen en el proceso de realización de una serie televisiva y que, siendo concluyentes como decisión final, conducen a la música a su uso mercenario y no estético-significativo:

1. Presupuestos económicos: es el principal aspecto puesto que, frecuentemente, la partida económica para la banda sonora es la que consta de menor aportación. En la banda sonora intervienen múltiples perfiles profesionales y, es lo que dará el carácter definitivo al producto audiovisual. Asesoramiento, composición o elección musical, grabación y edición suponen una parte importante de la realización. Un mayor o menor presupuesto puede suponer un resultado final de mayor o menor calidad artística.

2. Errores de filmación que, en el momento de la creación de la banda sonora, deben ocultarse (ruidos no deseados, por ejemplo). De esta manera, el uso de una música en una secuencia se convierte en obligatorio cuando, de hecho, no se había previsto ilustrarla durante el proceso de la creación y pre-producción del guión técnico-artístico.

3. Ritmos de montaje audiovisual no deseados que obligan al uso de música para modificarlos. Acostumbran a ser ritmos lentos que pueden llevar al espectador a una percepción aborrecida de la narrativa audiovisual, sin que sea ésta la pretensión del realizador. Se trata de errores en la formación de los planos y su edición: ritmos internos demasiado lentos y edición sin un planteamiento de ritmo narrativo-visual previo.

2. Si tomamos la nomenclatura anglosajona, quien dirige un proyecto audiovisual en televisión o en cine es llamado director; sin embargo, en el ámbito francófono, es llamado réalisateur. En España, diferenciamos si se trata de un director de cine o de un director de televisión: en el primer caso, se trata de director; sin embargo, en televisión, cualquier persona que dirija un proyecto audiovisual (magazine, informativos, conciertos u otros géneros audiovisuales televisivos) es llamada realizador/a. Durante este artículo, como se trata de una serie de ficción televisiva, usaré el nombre de realizador. 
4. Tiempo limitado para la creación de la banda sonora. Desde que se termina la filmación de la imagen, el margen de tiempo para terminar de plantear, pensar y trabajar en la banda sonora es muy limitado y el cuidado estético y profesional puede fracturar un resultado final de calidad.

5. La formación y la cultura del realizador pueden recortar la capacidad y la voluntad transgresora de lo que músicos o ambientadores musicales pueden aportar desde su profesionalidad. El uso de la música «del momento», es decir, dejarse llevar por la «modernidad» para llegar al público objetivo del proyecto audiovisual, quizás no es el planteamiento a partir del cual el realizador debe proyectar su labor creativa.

Estos cinco puntos- y podrían añadirse muchos otros desde la experiencia profesional de cada una de las personas que intervienen en la realización audiovisual- muestran lo que conduce, previamente, al obligado uso de una música. Son factores importantes, pero, al final, cuando un espectador ve una serie, no puede saber qué causas han provocado que una música ilustre una secuencia o no. Cualquier intencionalidad de uso musical con imágenes puede quedar enmascarada por razones muy alejadas de razones estéticas o narrativo-visuales.

Es por ello que, el análisis que quiero ofrecer del uso de la música en la serie Merlí sólo parte del momento en que llega ya a las pantallas de los espectadores, sin querer investigar más allá de lo que supone la preproducción de este proyecto.

\section{ELABORACIÓN DE LOS SIGNIFICANTES MÚSICO-VISUALES}

El papel que juega la música dentro de un film, o serie de ficción, es múltiple. Dicha función ha sido estudiada por musicólogos expertos en música incidental. Entre ellos, Zofia Lissa en su obra Music and film: Study on the borderline of ontology, aesthetics and psychology, del año 1937. Ha pasado casi un siglo desde dicho estudio y, por supuesto, el mundo audiovisual se ha desarrollado exponencialmente; principalmente si nos referimos a la técnica; sin embargo, las funciones de la música respecto a la imagen siguen siendo desarrolladas e investigadas y, aunque existen propuestas más o menos complejas que van enriqueciendo el rol musical ante la imagen, siempre nos encontramos con la fórmula básica:

Significante visual Significante Musical = Significante Músico-Visual

Es decir, cualquier significante musical actúa sobre un significante visual dando como resultado un nuevo significado músico-visual. La narrativa audiovisual, así pues, no viene sólo marcada por las imágenes, sino por la música e, incluso, la ausencia de ésta, nos está aportando una nueva significación. Es curioso constatar que una película como Le grand bleu tuvo dos bandas sonoras: una europea 
compuesta por el francés Eric Serra y, otra, americana compuesta por Bill Conti. No es ahora el momento de analizar ambas, pero sí este hecho nos puede llevar a plantear cómo un significante visual puede acompañarse de dos significantes musicales debido a que el director piensa en públicos cuya percepción y recepción serán muy distintas: público europeo y público americano. Así pues, imaginemos el efecto multiplicador de percepciones que pueden darse ante diversos significantes musicales que acompañen una misma significación visual. Se puede ampliar este interesante estudio de «doble banda sonora» en el artículo del compositor, investigador y director artístico Gérard Dastugue «La musique de film est-elle (un discours) univoque?».

Philipp Tagg, por su parte, adaptó las funciones de la música propuestas por Zofia Lissa y las reagrupó en diez funciones ${ }^{3}$. Otros musicólogos aportaron nuevas descripciones de significación musical en referencia a las imágenes. Música diegética o música empática son aportaciones de Michel Chion, musicólogo francés cuyos estudios y teorización en el ámbito del análisis músico-visual ya son un referente en cine y/o televisión.

Para la elaboración de un significante músico-visual, parto de la función de la música desde dos vertientes: narrativa y expresiva. Narrativa en cuanto a la forma y expresiva en cuanto a las emociones. En el uso de la música clásica dentro de la serie Merlí, podemos comprobar cómo dichas funciones se emplean de manera diáfana y constante.

\section{MERLÍN: POPULARIZACIÓN DE LA MÚSICA CLÁSICA4}

Para quien no conozca la serie $M$ erli $\hat{\imath}^{5}$, una breve sinopsis: el nuevo profesor Merlí Bergeron llega al Instituto Àngel Guimerà para impartir la asignatura de Filosofía a los alumnos de $1^{\circ}$ de Bachillerato. Su manera de enseñar la filosofía es totalmente transgresora y provoca gran desconcierto en el centro, no sólo a los otros docentes, sino también a los alumnos. A partir de sus clases y, a través de cada uno de los filósofos, les va conduciendo a través de la realidad de la vida. Enfermedades, amores y desamores no sólo entre adolescentes sino de entre adultos, relación entre padres e hijos y otros temas que desentraña el

3. https://www.tagg.org/udem/musimgmot/filmfunx.html (consultada el 25 de septiembre del 2018)

4. En la serie Merlí se usó música incidental creada para la sèrie y compuesta por Xavi Capellas; así como música clásico cuyos arreglos corrieron a cargo de Francesc Cassú y se grabaron los Estdios 441 d'Aiguaviva, en Gerona.

5. Serie coproducida por Televisió de Catalunya y la productora Veranda, y que, actualmente se puede encontrar en Netflix. Consta de tres temporadas, con trece capítulos las dos primeras y catorce capítulos, la tercera y última. 
guión, capítulo tras capítulo, son cuestiones que involucran a Merlí Bergeron en la vida de un curso escolar.

En el cuadro siguiente, presento el detalle del uso de la música clásica en cada uno de los capítulos de la primera temporada. El esquema informa del número del capítulo, el filósofo a quien se le dedica el número del capítulo, la música clásica empleada y el minutado o duración de la misma.

Tabla 1. Desglose de los capítulos de la serie Merlí en referencia al uso de la música clásica

\begin{tabular}{|c|c|c|c|}
\hline Capítulo & Filósofo & Música & Minutaje \\
\hline 1 & $\begin{array}{l}\text { «os } \\
\text { Peripatéticos» } \\
(1 \mathrm{x} 01)(2015) \\
\end{array}$ & $\begin{array}{l}\text { Minué en sol menor, de Johann } \\
\text { Sebastian Bach }\end{array}$ & $03: 00$ a $03: 30-30 "$ \\
\hline 2 & $\begin{array}{l}\text { «Platón» } \\
(1 \times 02)(2015)\end{array}$ & $\begin{array}{l}\text { Clair de Lune de Claude } \\
\text { Debussy- } \\
\text { (piano) }\end{array}$ & $46: 41$ a $48: 37-1{ }^{\prime} 56 "$ \\
\hline \multirow[t]{2}{*}{3} & $\begin{array}{l}\text { «Maquiavelo» } \\
(1 \times 03)(2015)\end{array}$ & $\begin{array}{l}\text { Vals op. } 64 \text { n.1, de F. Chopin. } \\
\text { Minué Vals / Vals du petit } \\
\text { chien (piano) }\end{array}$ & $36: 52-38: 12-1 ' 20 ”$ \\
\hline & & $\begin{array}{l}\text { Preludio n. } 1 \text { en Do Mayor, } \\
\text { BWV 346, de J. S. Bach (piano) }\end{array}$ & $46: 22-48: 53-3{ }^{\prime} 30^{\prime \prime}$ \\
\hline 4 & $\begin{array}{l}\text { «Aristóteles» } \\
(1 \mathrm{x} 04)(2015)-\end{array}$ & $\begin{array}{l}\text { Suite para cello n. } 1 \text { en G BWV } \\
1007 \text { J. S. Bach (violoncelo) }\end{array}$ & 42:07-44:02- 1’55” \\
\hline 5 & $\begin{array}{l}\text { «Sócrates» } \\
(1 \times 05)(2015)-\end{array}$ & $\mathrm{x}$ & $\mathrm{x}$ \\
\hline 6 & $\begin{array}{l}\text { «Schopenhauer» } \\
(1 \times 06)(2015)-\end{array}$ & $\begin{array}{l}\text { Aria para cuerda en Sol Mayor, } \\
\text { de J. S. Bach (violín y piano) }\end{array}$ & $15: 30$ a $17: 10-1{ }^{\prime} 40 "$ \\
\hline \multirow[t]{2}{*}{7} & $\begin{array}{l}\text { «Foucault» } \\
(1 \times 07)(2015)-\end{array}$ & $\begin{array}{l}\text { Gnosienne n. 1, de Erik Satie } \\
\text { (piano) }\end{array}$ & $14: 10-14: 42-32 ”$ \\
\hline & & $\begin{array}{l}\text { Lago de los cisnes, ballet suite } \\
\text { op. } 20 \text { Escena del Lago por la } \\
\text { noche, de P. I. Tchaykovsky. } \\
\text { Belgrad Philarmonic Orchestra }\end{array}$ & $46: 32-48: 30-1 ’ 58 ”$ \\
\hline 8 & $\begin{array}{l}\text { «Guy Debord» } \\
(1 \times 08)(2015)\end{array}$ & $\mathrm{x}$ & $\mathrm{x}$ \\
\hline 9 & $\begin{array}{l}\text { «picuro»(1x09) } \\
(2015)\end{array}$ & $\mathrm{x}$ & $\mathrm{x}$ \\
\hline
\end{tabular}


MARTA MILLÀ I BRUCH

MÚSICA CLÁSICA, SERIOUS MUSIC O MÚSICA CULTA EN LA SERIE DE TELEVISIÓN: MERLÍ. NI GRAFFITI DEL PRESENTE, NI ESTAMPITA DEL PASADO

\begin{tabular}{|c|c|c|c|}
\hline Capítulo & Filósofo & Música & Minutaje \\
\hline \multirow[t]{2}{*}{10} & $\begin{array}{l}\text { «Los escépticos» } \\
(1 \times 10)(2015)-\end{array}$ & $\begin{array}{l}\text { Preludio en mi menor Op. } 28 \mathrm{n} . \\
\text { 4, F. Chopin (piano) }\end{array}$ & $27: 50$ a $28: 52-1$ '02" \\
\hline & & $\begin{array}{l}\text { Lascia ch'io pange. Rinaldo. } \\
\text { Haëndel. }\end{array}$ & 43:13 a 44:20- 1'07" \\
\hline 11 & $\begin{array}{l}\text { «Los sofistas» } \\
(1 \times 11)(2015)-\end{array}$ & $\mathrm{x}$ & $\mathrm{x}$ \\
\hline 12 & $\begin{array}{l}\text { «Hume» } \\
(1 \times 12)(2015)-\end{array}$ & $\begin{array}{l}\text { Variaciones Goldberg BWV } \\
\text { 988- J. S. Bach }\end{array}$ & $49: 25$ a $52: 35-3^{\prime} 10^{\prime \prime}$ \\
\hline \multirow[t]{2}{*}{13} & $\begin{array}{l}\text { «Nietzsche» } \\
(1 \times 13)(2015)-\end{array}$ & $\begin{array}{l}\text { Vals op. } 64 \text { n.1, de F. Chopin. } \\
\text { Minué Vals (piano) }\end{array}$ & $00: 00-01: 45-1{ }^{\prime} 45^{\prime \prime}$ \\
\hline & & $\begin{array}{l}\text { Arabesque n. } 1 \text { Débussy } \\
\text { (piano) }\end{array}$ & 15:40-17:10-1'30" \\
\hline
\end{tabular}

Nota. Tabla con el desglose del uso de música clásica en la primera temporada de la serie Merlí, de M. Millà, 2018

Tras el análisis del uso de música clásica durante la primera temporada de Merlí, podemos ver que el tiempo no excede el $5 \%$ de la duración de cada capítulo; sin embargo, a pesar de que el uso no es excesivo, sí es importante en cuanto a los momentos vivenciales en que la música ilustra las imágenes. Otro aspecto a tener en cuenta es el momento temporal en el que aparece: en la mayoría, suele ser a final de capítulo. Así, tenemos tres datos a tener en cuenta:

- poca duración de la música clásica en cada capítulo.

- aparece hacia el final del capítulo, a modo conclusivo.

- aparece en momentos en que se quieren subrayar las emociones de los protagonistas.

A partir de este primer análisis, propongo dos elementos más de estudio acerca del uso de la música clásica: uso narrativo y uso descriptivo.

\section{EL USO NARRATIVO DE LA MÚSICA CLÁSICA EN MERLÍ}

Son muchas las funciones de la música dentro del mundo cinematográfico y, por extensión, dentro del mundo audiovisual televisivo. En la serie que nos ocupa, me parece interesante remarcar cómo el empleo narrativo se suma al empleo descriptivo emocional de cada una de las músicas que acompañan algunas secuencias. En tres capítulos (1x02, 1x06 y 1x10), aparece la imagen de transición elíptico-temporal representada por un búho. La misma música que sirve para 
comunicar los sentimientos de los personajes es la que se usa para representar el paso del tiempo: del día a la noche, o viceversa. Son músicas lentas; el Claro de Luna de Débussy, el Aria para cuerda en Sol Mayor de Johann Sebastian Bach y el Preludio en mi menor de Chopin. Este ritmo lento acompaña imágenes ralentizadas y con desenfocados. De esta manera se superponen el lenguaje visual y musical a través de un ritmo interno de cada plano.

Este tipo de transición funciona a modo de leitmotiv a través de los capítulos de la serie (lo mismo sucede en las siguientes temporadas). Como consecuencia, el espectador se sitúa en el cronograma del capítulo a través de la imagen del búho y de la música que la acompaña (en estos tres casos, música clásica) y deduce que se acerca el final. Comprobamos como el director no ha decidido escoger una música para la transición y otra para las acciones anteriores o posteriores, como suele verse en otras series en las cuales el signo de puntuación marcado por la música es evidente, sino que, más bien, quiere presentar este momento final como un bloque integrado en el que el espectador se sumerge en un ambiente emocional que le ayuda a pasar de un momento cronológico a otro de manera nada «invasiva», sino con una continuidad narrativo-visual. De este modo, sólo a través de la imagen, el espectador sabe que hay un salto en el tiempo y en el espacio; si sólo se guiara por la música, sería imposible percibir dicho salto elíptico. Es por ello, que el análisis expresivo del uso musical pasa a tener prioridad: el uso narrativo o estructural queda enmascarado por el uso expresivo.

\section{EL USO EXPRESIVO DE LA MÚSICA CLÁSICA EN MERLÍ}

No puedo referirme a un uso descriptivo de la música clásica por dos motivos. En primer lugar, se trata de una serie ambientada en un instituto de enseñanza actual (año 2015) ${ }^{6}$, no histórica; y, en segundo lugar, está localizada en Cataluña, concretamente, en Barcelona. Así pues, el hecho de usar música clásica de compositores anteriores a la actualidad no responde a la necesidad estética de referenciar la imagen culturalmente. En este caso, la música no describe una localización geográfica ni evoca un tiempo histórico.

¿Cómo se trata el uso expresivo de la música clásica?

En principio, la música presenta una intencionalidad cuando se suma a las imágenes y puede dar distintos significantes visual-musicales al resultado final:

- Expresar lo mismo que la imagen nos comunica; se trata, entonces, de una comunicación redundante.

6. Existen otras músicas o canciones que sí referencian una generación y una sociedad; pero, mi análisis se centra en la música clásica. 
MARTA MILLÀ I BRUCH

MÚSICA CLÁSICA, SERIOUS MUSIC O MÚSICA CULTA EN LA SERIE DE TELEVISIÓN: MERLÍ.

NI GRAFFITI DEL PRESENTE, NI ESTAMPITA DEL PASADO

- Expresar emociones o sentimientos que, con la imagen, no podemos comunicar.

- Expresar lo contrario de la imagen.

- No expresar nada; simplemente se trata de un acompañamiento neutro.

Podemos encontrar algunas de estas intencionalidades expresivas en los siguientes puntos de análisis.

\section{Música Diegética}

No se puede hablar de un uso diegético de la música riguroso en ninguna de las tres secuencias en las que se puede encontrar dicha manera de incorporar el elemento musical.

- Capítulo 1. Los Peripatéticos. Uso diegético ${ }^{7}$ del Minué del Álbum de Ana Magdalena Bach de Johann Sebastian Bach dentro de una clase de danza. Dos observaciones: no se puede afirmar que la música acompaña los ejercicios de la barra que realiza el alumno protagonista (Bruno) por dos motivos: el ejercicio de pliés no va acompañado nunca con música de minué. El minué es una danza barroca y no se corresponde con la imagen que vemos, tampoco se aprecia que el ritmo acompañe el ejercicio de barra. Por otro lado, en caso de ser diegética, cuando el punto de vista o ángulo se realiza desde fuera del aula, el sonido debería reducir su volumen. Es importante la acusmatización para situar al espectador dentro y fuera de la sala y que perciba que se trata de una música que también están oyendo los protagonistas. Nos encontramos ante un caso de música con función descriptivo-diegética; sin embargo, el desarrollo y rigurosidad de ambas no existe tal y como podemos comprobar al seguir la secuencia y, en principio, nada nos hace suponer que se trata, explícitamente de un caso de diégesis.

- Capítulo 6. Shopenhauer. Suena la Suite para violoncelo n. 1 en G de J. $\mathrm{S}$. Bach y vemos a Berta que escucha música con los auriculares acostada en la cama. Podría parecer música diegética, pero no lo es; como en el caso anterior, la música no suena ecualizada como si se estuviera oyendo por los auriculares. En toda la secuencia, la música mantiene el mismo volumen y ecualización. Además de potenciar el sentimiento

7. Música que es escuchada por los actores y cuya fuente sonora se ve en la imagen o se deduce que está dentro de la ambientación o escenografia. En este caso, la música suena dentro de la clase de danza a través de un reproductor de música. 
que la adolescente tiene en este momento, la música de Bach sirve como transición temporal y de situación. Pasamos de la noche al día con la misma música a través de la secuencia leitmotiv del búho.

- Capítulo 7. Foucault. La música de la escena del Lago de los cisnes de Tchaykovsky se inicia de manera diegética y pasa a ser no diegética o extradiegética en las secuencias posteriores. Es decir, empieza como música descriptiva del momento y termina como música que indica las emociones de algunos de los protagonistas. Lo que, en un principio, determina la diégesis del empleo de la música, es decir, el acompañamiento del baile del «cisne negro» dentro del aula, se frustra en el momento en que Merlí, desde fuera de la sala, puede escuchar esta música como si estuviera dentro de la misma. Parece que se trata más de un uso musical que aprovecha la escena del baile de Bruno y, a partir de ésta, sigue el desarrollo dramático del guión.

\section{Montaje Paralelo}

Un importante recurso técnico de edición es el montaje paralelo. El uso expresivo de la música en la serie Merlíse sostiene, principalmente, en secuencias editadas a través de esta técnica de montaje. Se trata de secuencias que ocurren al mismo tiempo, en distinto lugar y que aparecen enlazadas con la música como nexo de unión. En el conjunto de la temporada, dicha técnica funciona, podríamos decir, como leitmotiv; de la misma manera que el recurso narrativo de transición usa el búho como salto elíptico en el tiempo y en la localización.

Podemos apreciar este tipo de montaje en cinco capítulos. En todos ellos, este sistema de edición apoya el contenido dramático de los sentimientos personales de los protagonistas. Aparece casi al final de cada capítulo, lugar donde parece recaer el peso dramático resumido en secuencias lentas y sin apenas diálogos. Es importante destacar el uso de la música clásica para todas ellas y no de una canción que empatice con el público objetivo de la serie. Los cinco capítulos son los siguientes:

- Capítulo 3. Maquiavelo. Preludio n. 1 en Do Mayor, BWV 346, de J. S. Bach

- Capítulo 4. Aristóteles. Suite para violoncelo n. 1 en G BWV 1007, de J. S. Bach

- Capítulo 7. Foucault. Lago de los cisnes, de P. I. Tchaykovsky (escena del lago de noche)

- Capítulo 12. Hume. Variaciones Goldberg BWV 988- J. S. Bach 
- Capítulo 13. Nietzsche. Arabesque n. 1 Débussy

Como análisis de montaje paralelo, propongo el capítulo sobre Hume. El Aria de las Variaciones Goldberg de J. S. Bach se encarga de acompañar cinco secuencias que describen la situación emocional de tres personajes:

- Joan reconstruye el barco, metáfora del deseo de reconstrucción de la relación con su padre.

- Iván sigue la lucha para vencer sus problemas de inseguridad y de miedo ante la salida física al exterior

- Merlí se muestra solo y pensativo ante sus problemas.

Tres minutos conducidos por la conocida Aria de Bach en los que no hay casi diálogo, el ritmo de la edición es lento y el contenido emotivo es crucial: el capítulo termina con la noticia del fallecimiento de un profesor del Instituto que había sido objeto de burlas por parte de algunos alumnos.

La música de Bach ha sido usada en multitud de películas cinematográficas; así que no hay novedad en el uso de la misma dentro de los capítulos de Merlí (ciertamente, es el compositor de quien más músicas se ha empleado para la serie); sin embargo, resulta desconcertante que en una serie juvenil se le otorgue un papel principal como acompañante de del estado emocional de los adolescentes.

Bach, así como Chopin, Débussy, Satie o Tchaykovsky se convierten en una especie de «esperanto musical» frente a los sentimientos y emociones que se vehiculan a través del guión dramático. En ocasiones, Bach ayuda en la transmisión de sentimientos de tristeza, de miedo, de soledad; pero, al mismo tiempo, también en la transmisión de sentimientos de alegría, euforia, cólera o herida emocional. En cada capítulo que termina con dicho montaje en paralelo, podemos afirmar que la música de dichos compositores «empatiza» $\mathrm{y}$ «anempatiza» con los personajes de la serie. De esta manera, la música resulta empática cuando logra que el espectador se adhiera y sumerja a las emociones del actor y, por otro lado, la música se convierte en anempática cuando se muestra indiferente a aquellos sentimientos a los que acompaña. Según este último caso de acompañamiento musical, se refuerzan las emociones por el contrapunto audiovisual y multiplican el efecto expresivo de la música. Así, se puede decir que podemos ir desde la redundancia más absoluta hasta el contrapunto más alejado de lo que el espectador ve en ese momento. Según el análisis del uso de la música clásica en esta serie, las secuencias dramáticas a través de esos montajes en paralelo se apoyan más en dicha redundancia sobre la imagen y provocan que el espectador empatice desde la primera nota musical con los sentimientos de los personajes en cada una de las secuencias. Sin embargo, en el capítulo siete dedicado a Foucault, la Gnosienne n. 1 de Erik Satie no parece reflejar el sentimiento de cólera o contrariedad adolescente de Joan. La música 
MARTA MILLÀ I BRUCH

MÚSICA CLÁSICA, SERIOUS MUSIC O MÚSICA CULTA EN LA SERIE DE TELEVISIÓN: MERLÍ.

NI GRAFFITI DEL PRESENTE, NI ESTAMPITA DEL PASADO

anempática de Satie en ese momento provoca que el espectador se adhiera aún más a la soledad del adolescente ante sus sentimientos.

\section{«Mickey mousing»}

Conocido como el efecto de acompañar musicalmente cada una de las acciones dentro de los dibujos animados, encontramos dicho efecto en cualquier extremo estético que pueda subrayar la música en cuanto a movimientos o sentimientos. En el capítulo tercero (Maquiavelo), vemos un ejemplo de este uso expresivo. El Vals op. 64 n.1 de F. Chopin es el encargado de marcar el ritmo de la secuencia que, durante un minuto veinte segundos, acompaña a Merlí desde que sale de casa hasta que llega al museo CosmoCaixa para encontrarse, por supuesto, con astucia maquiavélica, con la madre del colegio (Gina) de quien se ha enamorado. Se trata de una secuencia con acción y escenas que contienen cierto acento cómico. No hay diálogo y la interpretación del vals de Chopin se adapta al ritmo de las imágenes hasta llegar al encuentro a través de las miradas. La ejecución, puesto que se trata de una versión grabada para la serie, realiza una pausa en el momento de dicho encuentro visual y se acaba la secuencia con la última frase musical. En este caso, nos encontramos con una doble funcionalidad musical: por un lado, marca el ritmo de la escena (desplazamiento de Merlí) y puntualiza algunas de las acciones (la mirada y el choque con el perro, por ejemplo). Parece ser, que se prioriza en este momento lo que podríamos llamar como «Mickey Mousing». Estamos ante un sincronismo redundante con la imagen y la emoción de los dos actores con un punto cómico puesto que saben que el encuentro no ha sido fortuito. El espectador, pues, se encuentra situado perfectamente en este juego de adolescencia que, evidentemente, es lo que añade un punto más de comicidad a la secuencia.

\section{POSTLUDIO}

¿Estamos ante un viaje iniciático de la música clásica? Bach, con sus Variaciones Goldberg o Suites para violoncelo; Chopin, con uno de sus vals; Satie con su Gnosienne...son obras ampliamente usadas en el mundo cinematográfico. Su capacidad de transmisión de emociones que traspasan la pantalla y empatan con el espectador no genera ninguna duda. Además, tres observaciones convierten este uso musical en una decisión importante:

- El uso de la música clásica se convierte en un rasgo distintivo dentro de una serie cuyo público objetivo son los adolescentes. Quizás, el director podría haberse decidido por una balada de rock; sin embargo, su apuesta ha sido un género, en principio, alejado de la juventud y opuesto al lenguaje usado en la serie: ni formal, ni académico, ni culto. 
- Sumerge al espectador en las emociones de los personajes de manera natural puesto que queda atrapado por las emociones a través de códigos musicales que han nacido del aprendizaje cultural.

- La integración, a través de la música clásica, de las funciones narrativa y expresiva dentro del montaje de varias secuencias unifica la percepción del espectador como si se tratara de un bloque único músico-visual y no de emociones dispersas en tiempo y lugar.

En definitiva, y como conclusión, la música clásica no debe quedar en el olvido como si se tratara de una «estampa del pasado", ni la debemos entender como un «graffiti del presente» que puede borrarse y, no sólo quedar, también, en el olvido, sino desaparecer en el más absoluto de los silencios. Así, pues, ya que este año celebramos el centenario del nacimiento del compositor Leonard Bernstein y, dado que el capítulo dedicado a Sócrates se ha quedado sin ilustrar musicalmente a través de la música clásica... ¿qué mejor opción que escuchar la obra de dicho compositor dedicada a El Banquete, de Platón (Diálogo con Sócrates), llamada Serenata? Las imágenes... en un nuevo capítulo.

\section{REFERENCIAS BIBLIOGRÁFICAS}

Baricco, Alessandro (1999). El alma de Hegel y las vacas de Wisconsin, Madrid: Ediciones Siruela.

Chion, Michel (1997). La música en el cine, Barcelona: Ediciones Paidós Ibérica, S. A.

Dastugue, Gérard (2015). «La musique de film est-elle (un discours) univoque?» En Muriel, J. et Merlier, B. La traduction des émotions dans les musiques des films, (pp. 31-45). Lyon: Département Musique et Musicologie de l’Université Lumière Lyon 2.

Lissa, Zofia (1937). Music and film: Study on the borderline of ontology, aesthetics and psychology, Lviv: Books Lviv.

\section{WEBGRAFÍA}

Lozano, Héctor (2015-2017). Merlí [serie de televisión]; España; Nova Veranda «Los peripatéticos» (1x01) (2015)- http://www.ccma.cat/tv3/alacarta/merli/capitol-1-elsperipatetics/video/5549976/[Última consulta: 25 de septiembre de 2018].

Lozano, Héctor (2015-2017). Merlí [serie de televisión]; España; Nova Veranda «Platón» (1x02) (2015)- http://www.ccma.cat/tv3/alacarta/merli/merli-plato-capitol-2/ video/5552234/ [Última consulta: 25 de septiembre de 2018].

Lozano, Héctor (2015-2017). Merlí [serie de televisión]; España; Nova Veranda «Maquiavelo» (1x03) (2015)- https://www.youtube.com/watch?v=WGxdm_TOJEo [Última consulta: 25 de septiembre de 2018]. 
Lozano, Héctor (2015-2017). Merlí [serie de televisión]; España; Nova Veranda «Aristóteles» (1x04) (2015)- https://www.youtube.com/watch?v=SgFhF6pXj2M [Última consulta: 25 de septiembre de 2018].

Lozano, Héctor (2015-2017). Merlí [serie de televisión]; España; Nova Veranda «Schopenhauer» (1x06) (2015)- https://www.youtube.com/watch?v=hBX1s1Zt1yU [Última consulta: 25 de septiembre de 2018].

Lozano, Héctor (2015-2017). Merlí [serie de televisión]; España; Nova Veranda «Foucault» (1x07) (2015)- https://www.youtube.com/watch?v=pUwXFNjqC6M [Última consulta: 25 de septiembre de 2018].

Lozano, Héctor (2015-2017). Merlí [serie de televisión]; España; Nova Veranda «Los escépticos» (1x10) (2015)- http://www.ccma.cat/tv3/alacarta/merli/merli-els-escepticscapitol-10/video/5564568/ [Última consulta: 25 de septiembre de 2018].

Lozano, Héctor (2015-2017). Merlí [serie de televisión]; España; Nova Veranda «Hume» (1x12) (2015)- https://www.youtube.com/watch? $=x 95$ hEEjQsEE [Última consulta: 25 de septiembre de 2018].

Lozano, Héctor (2015-2017). Merli [serie de televisión]; España; Nova Veranda «Nietzsche» (1x13) (2015)- https://www.youtube.com/watch?v=gTOQPGeWrFQ [Última consulta: 25 de septiembre de 2018].

Tagg, Philip (2012). «Functions of Film Music and miscellaneous terminology». Disponible en: <https://www.tagg.org/udem/musimgmot/filmfunx.html> [Última consulta: 25 de septiembre de 2018]. 